Черная И. П. Инновационные контуры геоэкономической конкурентоспособности России в цифровой эпохе

УДК 338.1:004(470):339.9

DOI dx.doi.org/10.24866/1813-3274/2019-3/37-52

И. П. Черная ${ }^{1}$, Тихоокеанский государственный медицинский университет Министерства здравоохранения Российской Федерации, г. Владивосток, Россия E-mail: rinach55@yandex.ru

\title{
ИННОВАЦИОННЫЕ КОНТУРЫ ГЕОЭКОНОМИЧЕСКОЙ КОНКУРЕНТОСПОСОБНОСТИ РОССИИ В ЦИФРОВОЙ ЭПОХЕ
}

Аннотачиия. В условиях распространения технологий и инноваций четвёртой промышленной революции вопросы формирования цифровой экономики в России приобретают важное значение. Оно определяется в том числе необходимостью повышения геоэкономической конкурентоспособности страны на мировых рынках. Поэтому в статье предпринята попытка переосмысления базовых положений геоэкономики в контексте усиления глобальной конкуренции и вызванного им стремлением развитых государств к инновационному перепозиционированию на основе развития цифрового потенциала. Рассматривая существующие подходы к оценке воздействия цифровой революции на глобальные процессы, автор выделяет геоэкономические особенности современного этапа глобализации как глобализации 4.0. Данный период глобализации связан с цифровизацией и цифровой трансформацией экономики и общества и имеет национальную, региональную, отраслевую и профессиональную специфику. Анализ геоэкономических вызовов цифровизации России на национальном и макрорегиональном уровне постсоветского пространства показывает сохранение страной статуса геоэкономического полюса силы. Угрозы и риски цифрового отставания РФ рассмотрены на основе данных докладов Всемирного банка «Конкуренция в цифровую эпоху: стратегические вызовы для России» и Евразийского банка развития - доклад «Цифровой потенциал стран - участниц ЕАБР». Это позволило сделать вывод, что для укрепления положения геоэкономического лидера в макрорегионе и повышения геоэкономической конкурентоспособности на глобальной арене РФ необходимо преодолеть противоречие между темпами цифровизации как процесса внедрения цифровых инноваций и уровнем и

\footnotetext{
${ }^{1}$ Ирина Петровна Черная, доктор экономических наук, профессор, Тихоокеанский государственный медицинский университет Министерства здравоохранения Российской Федерации, г. Владивосток, Россия.

Для циттирования: Черная И. П. Инновационные контуры геоэкономической конкурентоспособности России в цифровой эпохе // Азиатско-Тихоокеанский регион: экономика, политика, право. 2019. № 3. C. 37-52.

(С) Черная И. П., 2019
} 
глубиной цифровой трансформации, обусловленной изменением образа мышления и деятельности всех субъектов цифрового общества. Данное противоречие носит характер ключевой проблемы для страны и может быть преодолено на основе реализации программ развития информационной компетентности населения России всех возрастов с принятием во внимание отраслевой и профессиональной специфики в регионах страны.

Ключевые слова: геостратегия, геостратегический центр силы, геофинансы, геоэкономика, геоэкономическая конкурентоспособность, геоэкономическая конкуренция, геоэкономический полюс силы, геоэкономические инновации, геоэкономические ресурсы, глобализация 4.0, инновации, информация, цифровая революция, цифровая экономика, цифровая трансформация, цифровизация, цифровой потенциал, цифровой протекционизм, цифровые инновации, четвёртая промышленная революция.

Irina P. Chernaya ${ }^{1}$, Pacific State Medical University, Vladivostok, Russia E-mail: rinach55@yandex.ru

\section{INNOVATIVE CONTOURS OF RUSSIAN GEOECONOMIC COMPETITIVENESS IN THE DIGITAL AGE}

Abstract. In the context of technological progress and innovations of the fourth industrial revolution, the issues of forming the digital economy in Russia are becoming important being also determined by the need to improve the country's geoeconomic competitiveness in world markets. Therefore, the article attempts to rethink the basic principles of geoeconomics in the context of increased global competition and the striving of developed countries for innovative re-positioning based on the development of digital potential. The author considers the existing approaches to assessing the impact of the digital revolution on global processes and highlights the geoeconomic features of the modern stage of globalization as globalization 4.0. This period of globalization is associated with digitalization and the digital transformation of the economy and society and has national, regional, sectoral and professional characteristics. Analysis of the geoeconomic challenges of Russian digitalization at the national and macro-regional levels of the post-Soviet space shows that the country has retained the status of a geoeconomic pole of power. The threats and risks of Russia's digital lag are based on the data from the World Bank's "Competition in the Digital Age: Strategic Challenges for Russia" and the Eurasian De-

\footnotetext{
${ }^{1}$ Irina P. Chernaya, Doctor of Economics, Professor, Pacific State Medical University, Vladivostok, Russia. For citing: Chernaya Irina P. Innovative contours of Russian geoeconomic competitiveness in the digital age // PACIFIC RIM: Economics, Politics, Law. 2019. № 3. P. 37-52.
} 
Черная И. П. Инновационные контуры геоэкономической конкурентоспособности России в цифровой эпохе

velopment Bank report "Digital Potential of EABR Member Countries". This allowed us to conclude that in order to strengthen the position of the geoeconomic leader in the macroregion and increase geoeconomic competitiveness in the global arena of the Russian Federation, it is necessary to overcome the contradiction between the pace of digitalization as a process of introducing digital innovations and the level and depth of digital transformation due to a change in the way of thinking and activity of all subjects of the digital society. This contradiction is a key problem for the country and can be overcome through implementing the programs of developing informational competence of the Russian population of all ages, taking into account the industry and professional specifics in the country's regions.

Keywords: geostrategy, geostrategic power center, geofinance, geoeconomics, geoeconomic competitiveness, geoeconomic competition, geoeconomic power pole, geoeconomic innovation, geoeconomic resources, globalization 4.0, innovation, information, digital revolution, digital economy, digital transformation, digitalization, digital potential, digital protectionism, digital innovation, fourth industrial revolution.

\section{Введение}

Возникновение и бурное распространение цифровой революции приводит к серьёзным изменениям на мировой арене, связанным с беспрецедентными масштабами распространения информации как важнейшего геоэкономического ресурса. По экспертным оценкам, каждый день отправляется 207 миллиардов электронных писем, выкладывается 8,8 миллиарда видео на YouTube, осуществляется 4,2 миллиарда поисковых запросов в Google и делается 152 миллиона звонков в Skype. В этом цифровом, не имеющим границ пространстве смена декораций политических и экономических, явных и скрытых столкновений действующих и малоизвестных акторов становится настолько стремительной, что осложняется проведение не только полноценного научного анализа текущей ситуации, но и её футурологических/ прогностических оценок. Яркой иллюстрацией этого является высказывание американского исследователя Д. Рашкоффа, который, полемизируя с Э. Тофлером, считавшим, что в XX в. будущее наступало слишком быстро и люди не справлялись с этой скоростью, утверждает, что будущее уже наступило, а вместе с ним и новое восприятие реальности. Современное общество живет в моменте связывающего всё информационного потока. Поэтому не нужно думать о том, как адаптироваться к будущему, а необходимо жить в мире, где всё происходит одновременно и прямо сейчас. Это отражается не только в культуре потребления, развитии созданных в индустриальную эпоху политических институтов. Особое влияние цифровая культура оказывает на экономику, прежде всего на финансовый рынок, где, напри- 
мер, будущая стоимость акций постепенно теряет свою ценность. Теперь гораздо важнее стоимость в реальном времени [1]. Очевидно, что в новых условиях цифровой революции необходимо переосмысление базовых положений геоэкономики как науки, изучающей стремление современных государств разработать особую стратегию поведения, ориентированную на повышение конкурентоспособности страны на основе её инновационного перепозиционирования, завоевания дополнительных ресурсов и развития цифрового потенциала. В этом контексте заслуживает повышенного внимания проблема геоэкономических инноваций как нововведений, новых элементов, способов перераспределения мировых ресурсов и дохода, влияющих на повышение конкурентоспособности субъектов мирового хозяйства [2]. С учётом неоднозначного геоэкономического положения России на современном мировом рынке такое переосмысление имеет важное значение для развития экономической науки и хозяйственной практики. В рамках данной статьи рассмотрим изменение геоэкономической конкурентоспособности нашей страны, обусловленное сменой основных глобальных трендов.

\section{Особенности международной конкуренции в условиях глобализации 4.0}

Одним из наиболее важных факторов развития современной геоэкономики становится изменение форматов глобализации. Название её нового этапа - «глобализация 4.0» получило официальную поддержку на Всемирном экономическом форуме в Давосе не столько как признание влияния четвёртой промышленной революции на глобальную экономику, сколько как обозначение приближающегося сдвига в глобализованных структурах, вызванного цифровыми технологиями в сочетании с быстро меняющейся мировой экономикой, социальным неравенством и политической напряжённостью как на международном уровне, так и внутри отдельных стран [3]. Данный феномен уже оказался в центре внимания многих исследователей, которые вслед за Клаусом Швабом - автором концепции «Индустрия 4.0» пытаются определить направления и масштабы перемен современной глобальной экономики как всё более конфликтной, многополярной, предвещающей фрагментированный, но связанный мир [4].

В этом мире складываются новые факторы международной конкурентоспособности, связанные прежде всего с потенциалом и скоростью внедрения цифровых технологий в производственные процессы различных стран. Согласно данным китайской компании Huawei, в 2016 г. цифровая экономика во всём мире оценивалась в 11,5 трлн долл., или 15,5\% мирового ВВП. Ожидается, что она будет расти в два раза быстрее, чем «аналоговая» экономика, и к 2025 г. её вклад в мировой ВВП может достигнуть более 24\%. В геоэкономических координатах вполне закономерен вопрос о лидерах новой эпохи. Рассматривая данную про- 
Черная И. П. Инновационные контуры геоэкономической конкурентоспособности России в цифровой эпохе

блему, Т. Петерсен выделяет три основных центра цифровой конкуренции с учётом динамики роста ВВП и ВВП на душу населения: западную индустриальную экономику, развивающиеся экономики стран Азии и Африки. Рисками для этих полюсов конкуренции исследователь называет не только темпы цифровой трансформации, но и старение населения и государственный долг, что может стать тормозом для стран Запада. Напротив, в государствах Азии и Африки, несмотря на существующие проблемы экономического роста, есть возможности для технологического скачка. Например, без установки стационарного телефона установить мобильную связь и, следовательно, оказаться на том же технологическом уровне, что и промышленно развитая страна [5]. Этот фактор конкурентоспособности отмечается и М. Мюхлейзеном [6], подчёркивающим, что менее развитые страны являются лидерами цифровизации во многих областях, таких как мобильные платежи (Кения), цифровая регистрация земли (Индия) и электронная коммерция (Китай). Важнейшим преимуществом этих стран стало отсутствие устаревшей инфраструктуры внедрения инноваций.

Необходимо отметить, что лидерство в глобализации 4.0 остается дискуссионным вопросом. Р. Болдуин утверждает, что глобализация 1.0 и 2.0 помогла G7. Глобализация 3.0 создала возможности для прорыва шести развивающихся странам, которые предлагает называть «Rapidly Industrialising 6», или сокращенно I6 - Китай, Южная Корея, Индия, Польша, Индонезия, Таиланд. При этом особенностью первых глобализаций было использование национальными экономиками своих сравнительных преимуществ, в рамках третьей глобализации в выигрыше оказались фирмы, которые смогли повысить конкурентоспособность, комбинируя национальные источники сравнительных преимуществ на основе международных производственных сетей. Победителей глобализации 4.0. нужно искать не на уровне стран или отраслей, а стадий производства и конкретных профессий [7]. Влияние цифровизации на экономику разных стран признаётся достаточно противоречивым. Это прослеживается прежде всего на рынке труда, где, по прогнозам экспертов, в течение следующих 10-15 лет значительные потери рабочих мест маловероятны, но с 2040/50 гг. эффекты разрушения рабочих мест могут перевесить их потери. Предполагается, что человеческие ресурсы будут всё больше заменяться производственным капиталом и технологиями, именно в эту область сместится распределение доходов. Как следствие, доля заработной платы в общественном доходе будет снижаться, особенно для низкоквалифицированных работников [8]. Для снижения рисков изменения конкурентных позиций государств в процессе цифровой трансформации и сохранения социальной стабильности прогнозируется изменение характера государственной социальной политики: современное общество потребления должно приблизиться к «общему пользованию и заботе о людях» («sharing and caring») - идейной сердцевине глобализации 4.0 [9]. 
Заслуживает внимания и анализ формирующихся цифровых инноваций как подсистемы геоэкономических инноваций новой эпохи. Как утверждают эксперты американской компании Mendix Inc., цифровые инновации по своей сути представляют использование цифровых технологий и приложений для улучшения существующих бизнес-процессов и повышения эффективности рабочей силы, повышения качества обслуживания клиентов и запуска новых продуктов или бизнесмоделей. Цифровые инновации предшествуют цифровой трансформации общества и экономики, которая определяется как переход от индустриальной эпохи, характеризуемой аналоговыми технологиями, к эпохе знаний, основанной на цифровых технологиях [10]. Среди таковых в последнее время всё большее внимание уделяется искусственному интеллекту. В этом плане особый геоэкономический смысл приобретают слова президента России В. В. Путина, сказанные 1 сентября 2017 г. в рамках Всероссийского открытого урока о том, что за искусственным интеллектом будущее, именно в этой области сосредоточенны колоссальные возможности и трудно прогнозируемые угрозы: тот, кто станет лидером в этой сфере, будет властелином мира. Неслучайно в научной литературе наблюдается повышенная активность изучения проблем цифровой конкурентоспособности стран, в том числе и потому, что «цифровой протекционизм» может стать реальным тормозом для современной глобализации, единственный сектор развития которой сейчас заключён в цифровой экономике [11].

Таковы лишь некоторые особенности нового этапа глобализации, ключевыми характеристиками которого являются возникновение цифровых инноваций и последующая цифровизация как процесс внедрения цифровых технологий для повышения эффективности и результативности всех процессов в производстве, бизнесе, науке, социальной сфере и повышения уровня и качества жизни населения. Цифровизация экономики как основной фактор цифровой революции носит глобальный характер, но темпы её распространения, как и скорость цифровой трансформации, имеют не только национальную, региональную, отраслевую и даже профессиональную специфику. Рассмотрим геоэкономические аспекты возможностей вхождения в новую глобализацию у России.

\section{Геоэкономические вызовы цифровизации России}

В новых условиях цифровой революции понимание геоэкономики как науки, изучающей экономические вопросы распределения и перераспределения ресурсов на основе выбора конкурентной стратегии государства с учётом факторов глобального и локального развития, нуждается в значительном дополнении. Выделенные нами ранее особенности данной науки стадии постглобализации, включая формирование и реализацию странами геостратегий самообеспечения стратегическими ресурсами, в том числе геофинансами, для создания устойчивых конкурентных 
Черная И. П. Инновационные контуры геоэкономической конкурентоспособности России в цифровой эпохе

преимуществ в международной сети [12], необходимо расширить за счёт вовлечения в предметное поле анализа факторов и результатов цифровой революции.

Прежде всего проанализируем изменения геоэкономических сил в мировой экономике. В соответствии с законом «полюса» О. Арина, в геоэкономическом пространстве такой статус получает страна, которая обладает превосходством экономической мощи над экономическим потенциалом вслед идущего государства как минимум в два раза. Геостратегическим центром силы страна становится, если объём её внешнеполитического потенциала превосходит аналогичный показатель конкурента как минимум в 2 раза на региональном уровне и в 4 раза на глобальном [13].

По прогнозам МВФ [14], в 2019 г. ВВП США составит почти 21,35 трлн долл. США. Эта страна по-прежнему возглавляет рейтинг стран по абсолютному показателю ВВП, однако она уже не может считаться глобальным геоэкономическим полюсом силы, т.к. показатель следующего в рейтинге Китая почти 14,2 трлн долл. США. Таким образом, разрыв между лидерами рейтинга составляет 1,5 раза, что меньше требуемого по закону «полюса». При этом КНР остаётся региональным лидером: ВВП Японии, по экспертным оценкам, составит около 5,2 трлн долл. Отметим, что такое положение наблюдается с 2010 г. США остаются региональным лидером в Северной Америке (ВВП Канады 1,82 трлн долл. США). Россия с ВВП в 1,7 трлн долл. США сохраняет роль регионального лидера на постсоветском пространстве: Казахстан имеет 190,1 млрд долл. США.

Расчёт показателя геостратегического центра силы значительно затруднён, т.к. по методике О. Арина необходимы показатели, характеризующие расходы на внешнюю политику и складывающиеся из финансовых потоков, закладываемых в бюджет страны и реализуемых через аппарат внешней политики (министерство иностранных дел, министерство обороны, информационно-пропагандистские службы, пограничная охрана, внешнеэкономические организации, службы внешней безопасности или разведки и т.д.). Поэтому ограничимся информацией по военным расходам. Показательны данные ежегодного доклада Стокгольмского международного института исследования проблем мира (SIPRI). Лидером в рейтинге расходов являются США, которые впервые с 2010 года в 2018 году увеличили их на 4,6\%, и они достигли 649 млрд долл., что равно совокупным тратам следующих в рейтинге восьми стран. На втором месте в рейтинге Китай, увеличивший свои расходы на 5\% - до 250 млрд долл. В целом военные расходы в мире в 2018 г. составили 1,8 трлн долларов, что на 2,6\% выше показателей предыдущего года [15].

Подобный анализ расклада сил в условиях цифровой революции является неполным, т.к. не учитывает инновационные форматы конкуренции, требующие оценки рисков и угроз, не только на международном, государственном, региональном уровнях. Как показывает анализ, глобализация 4.0. сопровождается усилением отраслевых и профессиональных вызовов. Поэтому для оценки возможностей фор- 
мирования геостратегии, соответствующей императивам эпохи, для укрепления или достижения положения геоэкономического лидера как полюса и/или центра силы необходимо учитывать возрастающее влияние цифровизации на экономику. Учитывая ограниченность исследований по этому вопросу, воспользуемся данными отчета McKinsey, в соответствии с которыми в США объём цифровой экономики уже достиг 10,9\% от ВВП, а ожидаемый прирост стоимости, создаваемый цифровыми технологиями, к 2025 г. может составить 1,6-2,2 трлн долл. КНР имеет сопоставимые показатели, и к 2025 г. эксперты прогнозируют рост объёма цифровой экономики до 22\%. Россия отстаёт и в объёме, и динамике цифровизации. В 2015 г. объём цифровой экономики в нашей стране составил 3,9\% ВВП, к 2025 г. он может увеличиться до 8-10\% и составить от 19 до 34\% общего ожидаемого роста ВВП. По уровню цифровизации частных компаний РФ также отстает от стран-лидеров. Объём инвестиций частных компаний в цифровизацию составляет пока всего 2,2\% от ВВП, тогда как в США он достигает 5\%, в странах Западной Европы - 3,9\%, в Бразилии - 3,6\%. По оценкам экспертов, разным будет и влияние цифровизации на рынок труда: в КНР и России до $18 \%$ работников будут вынуждены сменить род деятельности, в США данный показатель составит 22\%, в Японии - 26\% [16]. Конечно, приведёные данные не позволяют создать полную картину рисков и угроз цифрового отставания РФ от лидеров. Однако вполне очевидно, что такие темпы развития цифровой революции в нашей стране не позволят ей сохранять, а тем более увеличивать конкурентоспособность на мировом рынке. Сфера геоэкономической конкуренции в современный период смещается в цифровую экономику, и для обеспечения экономической безопасности государства необходима не столько цифровизация, сколько усиленная политической волей государства цифровая трансформация экономики как непрерывный процесс преобразования и повышения эффективности бизнеса путём изменения образа мышления и деятельности всех субъектов цифрового общества. Для создания проактивных механизмов цифровой трансформации необходимо проанализировать проблемы и перспективы цифровизации российской экономики.

\section{Проблемы и перспективы цифровизации в России}

Для определения основных направлений решения поставленной задачи воспользуемся двумя экспертными исследованиями, связанными с изучением различных сторон цифровизации и цифровой трансформации.

В сентябре 2018 г. Всемирный банк опубликовал подготовленный в сотрудничестве с Институтом развития информационного общества (ИРИО), Аналитическим центром при Правительстве Российской Федерации и другими российскими организациями доклад о развитии цифровой экономики в РФ «Конкуренция в цифровую эпоху: стратегические вызовы для России», в котором страна охарактеризо- 
Черная И. П. Инновационные контуры геоэкономической конкурентоспособности России в цифровой эпохе

вана как претендент на роль одного из глобальных цифровых лидеров. Созданная для данного исследования методика оценки уровня развития цифровой экономики - Digital Economy Country Assessment (DECA) помогает выявить ключевые пробелы, проблемы и возможности для будущего роста, а также области, требующие более тщательного анализа. Основой исследования является изучение трёх групп факторов, обеспечивающих экономические и социальные преобразования: нецифровых факторов (политика, стратегическое планирование, лидерство и институты, законодательство, человеческий капитал, инновации, деловая среда, доверие и безопасность); цифровых факторов (цифровая инфраструктура, совместно используемые цифровые платформы и нарождающиеся цифровые технологии); цифрового сектора экономики (сектор информационно-коммуникационных технологий, а также сектор контента и средств массовой информации). Данные факторы оказывают воздействие на государственный и частный секторы, а также на общество в целом (цифровые граждане и потребители), поэтому в методике предусмотрена оценка цифровой трансформации названных секторов, которая оказывает существенное воздействие на экономические и социальные процессы, прежде всего на экономический рост, рынок труда и качество обслуживания. Каждая предметная область оценивается по пятибалльной системе и характеризуется набором из пятнадцати показателей, включающих количественные (в том числе используемые международными организациями) и качественные, характеризующие важные аспекты развития, но не имеющие метрик. Согласно полученным результатам РФ имеет экспертную оценку на уровне 4 баллов по 5 показателям (человеческий капитал, доверие и безопасность, цифровая инфраструктура, цифровые платформы и новые цифровые технологии) и на уровне 3 баллов по 10 показателям (государственная политика и стратегическое планирование, лидерство и институты, законодательство, НИОКР и инновации, бизнес среда, цифровой сектор экономики, цифровая трансформация госсектора, цифровая трансформация бизнеса, цифровые граждане, социальные и экономические эффекты) [17]. Это позволяет сделать определённые выводы в контексте геоэкономических задач государства в новой эпохе. Как и в предыдущие периоды, наша страна обладает большим ресурсным потенциалом, в данном случае цифровым, - как готовности и возможности РФ включиться в глобальную цифровую экономику, однако по-прежнему ей не хватает эффективных институциональных механизмов управления, обеспечивающих проведение проактивной конкурентной политики в новых сферах и нарождающихся рынках для развития собственного геоэкономического пространства. Подобные выводы подкрепляются и анализом других исследований.

С точки зрения развития РФ как регионального геоэкономического полюса силы на постсоветском пространстве особое значение имеет изучение цифрового потенциала страны с учётом данного региона. В этом плане представляет интерес до- 
клад «Цифровой потенциал стран - участниц ЕАБР» [18], подготовленный сотрудниками Центра интеграционных исследований Дирекции по аналитической работе Евразийского банка развития (ЕАБР) в июле 2019 г. В нём особое внимание уделено сравнению динамики роста доступа к интернету населения и индекса цифрового внедрения (ИЦВ), рассчитываемого Всемирным банком. Значимость этих показателей определена фундаментальной ролью Интернета в цифровой экономике для создания особой экосистемы, меняющей кардинальным образом характер и конкурентоспособность традиционных сфер. Индекс цифрового внедрения используется в 180 странах и фиксирует уровень распространения и использования цифровых технологий тремя главными агентами экономики: бизнесом, населением и государством. На основе индикаторов по трём экономическим участникам рассчитывается среднестатистический общий индекс ИЦВ.

В соответствии с результатами исследования цифровыми лидерами в регионе являются Россия, Казахстан и Армения. При этом РФ с показателем 0,74 удерживает первенство в ИЦВ (значения показателей Казахстана и Армении соответственно $0,67$ и 0,62$)$. По индикатору бизнеса, который включает в себя технологии, необходимые для повышения производительности и ускорение общего роста бизнеса, Россия с Арменией со значением показателя 0,71 уступают Беларуси с её показателем 0,74. По индикатору населения, характеризующего технологии, необходимые для расширения возможностей и повышения благосостояния людей, Россия также лидирует со значением показателя 0,70 , далее следуют Беларусь $(0,66)$ и Казахстан $(0,57)$. По индикатору госсектора, который позволяет представить уровень развития технологий для повышения эффективности предоставления услуг для правительства, РФ занимает второе место со значением показателя 0,82, что на 0,02 меньше значения показателя Казахстана. Как видим, показатель индикатора госсектора является наибольшим для России. Однако вывод авторов доклада, что главной движущей силой цифровой трансформации в нашей стране является госсектор, представляется неверным, поскольку рассматриваемые показатели демонстрируют скорее процесс цифровизации.

Доказательством этому являются приводимые в исследовании ключевые показатели конкурентоспособности экономик стран - участниц ЕАБР в области цифровизации, которые в своём большинстве отражают процесс внедрения цифровых инноваций. Подчеркнём, что данные показатели также показывают цифровое лидерство РФ в регионе. Из десяти ключевых показателей конкурентоспособности по шести наша страна лидирует (Индекс электронного правительства как использование онлайн-сервисов для облегчения предоставления правительством информации гражданам, взаимодействия с заинтересованными сторонами и участия в процессах принятия решений; Абоненты мобильной сотовой связи; Подписка на мобильный широкополосный Интернет; Подписка на фиксированный широкополосный Интер- 
Черная И. П. Инновационные контуры геоэкономической конкурентоспособности России в цифровой эпохе

нет; Интернет-подписка «волокно на дом/здание»; Знание цифровых технологий и компьютерная грамотность среди дееспособного населения). По показателю доли Интернет-пользователей среди населения Россия занимает второе место, уступая Казахстану. По трём показателям (Ориентированность правительства на будущее; Гибкость правовой базы страны к цифровым бизнес-моделям; Скорость роста инновационных компаний) РФ находится на третьем месте в данном рейтинге. Между тем только эта третья группа показателей имеет отношение к цифровой трансформации экономики как отражение экспертной оценки изменения цифровой культуры, т. к. ориентированность правительства - на будущее; гибкость правовой базы страны к цифровым бизнес-моделям определяется на основе средних значений ответов на вопросы опроса. При этом результаты РФ по этим показателям не превышают 3,9 из 7 возможных баллов. Поэтому рекомендации, сделанные в докладе «Цифровой потенциал стран - участниц ЕАБР» о финансировании развития цифровой инфраструктуры, обеспечении необходимой правовой базы для цифровизации бизнеса и гибкости госструктур к принятию новых технологий являются недостаточными для необходимой стране цифровой трансформации, т. к. меры в этом направлении разработаны и реализуются в рамках принятой в 2017 г. программы «Цифровая экономика Российской Федерации». Например, по данным сайта Минкомсвязи России, в течение пяти лет на развитие и внедрение «сквозных» цифровых технологий планируется направить свыше 200 млрд руб. бюджетного финансирования и ещё привлечь несколько сотен миллиардов частных средств. Большая часть госрасходов пойдет на целевые субсидии затрат на НИОКР, внедрение решений и софинансирование венчурных инвестиций. Проведённый анализ показывает, что к важнейшим проблемам цифровизации нашей страны относится низкий уровень качества жизни населения, поскольку существует зависимость между показателями ВВП на душу населения в долларах США, скоростью распространения цифровых инноваций и доверия к ним, а значит и «цифровой культурой» общества. Иначе говоря, даже большие инвестиции в цифровую экономику, полученные в результате перераспределения средств из «традиционной» экономики, сами по себе не стимулируют экономический рост и не способствуют цифровой трансформации.

Подведём некоторые итоги. Под действием четвёртой промышленной революции современное общество вступило в стадию глобализации 4.0, важнейшей сферой развития которой является цифровая экономика. Темпы её становления связаны с цифровизацией - процессом внедрения и распространения цифровых инноваций и цифровой трансформацией как непрерывным преобразованием и повышением эффективности бизнеса путём изменения образа мышления и деятельности всех субъектов цифрового общества. Данные процессы носят глобальный характер, но имеют национальную, региональную, отраслевую и профессиональную специфику, что требует поиска новых проактивных механизмов реализации геостратегий инно- 
вационного перепозиционирования и развития цифрового потенциала страны для повышения её геоэкономической конкурентоспособности на мировых рынках. Это имеет принципиальное значение для России, которой пора перейти от стадии осмысления геоэкономической стратегии к её формализации с учётом инновационных факторов цифровой эпохи.

Геоэкономическое положение страны по-прежнему нельзя оценить однозначно. Анализ факторов цифровизации (цифровая инфраструктура, цифровые платформы, доступ к Интернету населения и др.) позволяет рассматривать РФ как одного из претендентов на лидерство, преимущественно на постсоветском пространстве. Однако изучение факторов цифровой трансформации бизнеса, государственного и потребительского секторов показывает, что реальные уровень и глубина трансформации являются скорее отражением угроз и рисков снижения, чем источниками повышения конкурентоспособности. Таким образом, ключевой проблемой повышения геоэкономической конкурентоспособности России является преодоление противоречия между темпами цифровизации и уровнем и глубиной цифровой трансформации. Для закрепления существующих и усиления лидирующих позиций в цифровой экономике необходимо параллельно с инвестициями в НИОКР и внедрением цифровых технологий особое внимание обратить на программы развития информационной компетентности населения всех возрастов, включая разработку стандартов обучения, методик оценки вовлеченности граждан в цифровую экономику, их способности совершать покупки и оплачивать услуги онлайн, использования цифровых устройств, мобильной связи и др. и методов стимулирования и мотивации для преодоления возрастного разрыва с принятием во внимание региональной, отраслевой и профессиональной специфики.

\section{Список литературы}

1. Rushkoff, D. Present shock: when everything happens now / D. Rushkoff. [New York] : Penguin, 2013. - 304 p. - ISBN: 978-1-59184-476-1

2. Кибальник, Л. А. Геоэкономические инновации как фактор экономического развития // Социально-экономические и финансовые механизмы обеспечения инновационного развития экономики : тезисы докладов III Международной научнопрактической конференции, 20-21 сент. 2012 г. / Государственный институт управления и социальных технологий БГУ. - Минск, 2012. - URL: http://elib.bsu.by/bitstream/123456789/19887/1/\%D0\%9A\%D0\%B8\%D0\%B1\%D0\%B0 $\% \mathrm{D} 0 \% \mathrm{BB} \% \mathrm{D} 1 \% 8 \mathrm{C} \% \mathrm{D} 0 \% \mathrm{BD} \% \mathrm{D} 0 \% \mathrm{~B} 8 \% \mathrm{D} 0 \% \mathrm{BA} \% \mathrm{0D} \% 93 \% \mathrm{D} 0 \% \mathrm{~B} 5 \% \mathrm{D} 0 \% \mathrm{BE} \% \mathrm{D} 1$ $\% 8 \mathrm{D} \% \mathrm{D} 0 \% \mathrm{BA} \% \mathrm{D} 0 \% \mathrm{BE} \% \mathrm{D} 0 \% \mathrm{BD} \% \mathrm{D} 0 \% \mathrm{BE} \% \mathrm{D} 0 \% \mathrm{BC} \% \mathrm{D} 0 \% \mathrm{~B} 8 \% \mathrm{D} 1 \% 87 \% \mathrm{D} 0 \% \mathrm{~B} 5 \%$ D1\%81\%D0\%BA\%D0\%B8\%D0\%B5\%20\%D0\%B8\%D0\%BD\%D0\%BD\%D0\%BE\%D 0\%B2\%D0\%B0\%D1\%86\%D0\%B8\%D0\%B8.pdf (дата обращения: 31.12.2019). 
Черная И. П. Инновационные контуры геоэкономической конкурентоспособности России в цифровой эпохе

3. Roylance, W. Davos was all about globalization 4.0, so what does it mean? // Diplomati courier. March 13. 2019. - URL: https://www.diplomaticourier.com/pos ts/davos-was-all-about-globalization-4-0-so-what-does-it-mean (дата обращения: 31.12.2019).

4. Eggel, D. Globalisation unbound: Transnational flows in the Digital Era / D. Eggel, M. Galvin // Global Challenges. - 2018. - Iss. 3, March. - URL: https://glob alchallenges.ch/issue/3/globalisation-unbound-transnational-flows-in-the-digital-era/ (дата обращения: 31.12.2019).

5. Petersen, Th. Digital Economy: How is digitalization changing global competitiveness and economic prosperity? - URL: https://ged-project.de/blogpostsen/digitaleconomy-how-is-digitalization-changing-global-competitiveness-and-economicprosperity/?cn-reloaded=1 (дата обращения: 31.12.2019).

6. Mühleisen, M. The long and short of the digital revolution // Finance \& Development. - 2018. - Vol. 55, no. 2. - P. 6-8. - URL: https://www.imf.org/external/pubs /ft/fandd/2018/06/impact-of-digital-technology-on-economic-growth/muhleisen.pdf (дата обращения: 31.12.2019).

7. Болдуин, Р. Великая конвергенция: информационные потоки и новая глобализация / Р. Болдуин. - Москва : Издательский дом «Дело» РАНХиГС, 2018. 416 c. - ISBN: 978-5-7749-1317-6.

8. Petersen, T. The bigger picture. How globalization, digitalization and demographic change challenge the world. - URL: https://ged-project.de/research/studies/the-biggerpicture/ (дата обращения: 31.12.2019).

9. Березной, А. Транснациональный бизнес в эпоху глобальной цифровой революции // Мировая экономика и международные отношения. - 2018. - Т. 62, № 9. - C. 5-17.

10. Your guide to driving digital innovation. - URL: https://www.mendix.com/digital-innovation/\#targetText=What\%20is\%20Digital\% 20Innovation $\% 3 \mathrm{~F}$,Irrespective $\% 20 \mathrm{of} \% 20$ the \& targetText=At $\% 20$ its $\% 20$ core $\% 2 \mathrm{C} \% 20 \mathrm{dig}$ ital\%20innovation,new\%20products\%20or\%20business\%20models (дата обращения: 31.12.2019).

11. The Rise of Digital Protectionism. Insights From a CFR Workshop. - URL: https://www.cfr.org/report/rise-digital-protectionism (дата обращения: 31.12.2019).

12. Черная, И. П. Геоэкономические факторы развития экономических циклов в современную эпоху // Таможенная политика России на Дальнем Востоке. - 2018. - № 2 (83). - C. 15-24.

13. Прогноз развития мировых отношений в XXI веке // Космонавтика XXI века. Попытка прогноза развития до 2101 г. / под ред. Е. Чертока. - Москва : РТСофт, 2010. - C. 483-554. 
14. Годовой отчет МВФ 2018 : Построение единого будущего. - Режим доступа: https://www.imf.org/external/pubs/ft/ar/2018/eng/assets/pdf/imf-annual-report-2018ru.pdf (дата обращения: 31.12.2019).

15. Armament and disarmament. - URL: https://www.sipri.org/research/armame ntand-disarmament (дата обращения: 31.12.2019).

16. Цифровая Россия: новая реальность / А. Аптекман, В. Калабин, В. Клинцов, Е. Кузнецова, В. Кулагин, И. Ясеновец ; Digital McKinsey. - URL: https://www.mckinsey.com/ru/ /media/McKinsey/Locations/Europe\%20and\%20Middle \%20East/Russia/Our\%20Insights/Digital\%20Russia/Digital-Russia-report.ashx (дата обращения: 31.12.2019).

17. Конкуренция в цифровую эпоху: Стратегические вызовы для Российской Федерации / Всемирный банк. - URL: https://www.vsemirnyjbank.org/ru/ country/russia/publication/competing-in-digital-age (дата обращения: 31.12.2019).

18. Цифровой потенциал стран - участниц ЕАБР / Центр интеграционных исследований. 2019. 06. - URL: https:/eabr.org/upload/iblock/551/EABR_Di gital_Potential_06_2019.pdf (дата обращения: 31.12.2019).

\section{References}

1. Rushkoff D. Present shock: when everything happens now. Penguin, 2013. 304 p.

2. Kibalnik L.A. Geoekonomicheskie innovatsii kak faktor ekonomicheskogo razvitiya [Geoeconomic innovation as a factor of economic development]. Sotsial'noekonomicheskie $i$ finansovye mekhanizmy obespecheniya innovatsionnogo razvitiya ekonomiki [Social, economic and financial mechanisms for innovation development of the economy: thes. III International science-practical conf. 20-21 Sep 2012. State Institute of Management and Social Technology BSU]. Minsk, 2012. Available at: http:/elib.bsu.by/bitstream/123456789/19887/1/\%D0\%9A\%D0\%B8\%D0\%B1\%D0\%B0 $\% \mathrm{D} 0 \% \mathrm{BB} \% \mathrm{D} 1 \% 8 \mathrm{C} \% \mathrm{D} 0 \% \mathrm{BD} \% \mathrm{D} 0 \% \mathrm{~B} 8 \% \mathrm{D} 0 \% \mathrm{BA} \% \mathrm{D} 0 \% 93 \% \mathrm{D} 0 \% \mathrm{~B} 5 \% \mathrm{D} 0 \% \mathrm{BE} \% \mathrm{D} 1$ $\% 8 \mathrm{D} \% \mathrm{D} 0 \% \mathrm{BA} \% \mathrm{D} 0 \% \mathrm{BE} \% \mathrm{D} 0 \% \mathrm{BD} \% \mathrm{D} 0 \% \mathrm{BE} \% \mathrm{D} 0 \% \mathrm{BC} \% \mathrm{D} 0 \% \mathrm{~B} 8 \% \mathrm{D} 1 \% 87 \% \mathrm{D} 0 \% \mathrm{~B} 5 \%$ D1\%81\%D0\%BA\%D0\%B8\%D0\%B5\%20\%D0\%B8\%D0\%BD $\%$ D0\%BD $\%$ D0\%BE $\% \mathrm{D}$ $0 \% \mathrm{~B} 2 \% \mathrm{D} 0 \% \mathrm{~B} 0 \% \mathrm{D} 1 \% 86 \% \mathrm{D} 0 \% \mathrm{~B} 8 \% \mathrm{D} 0 \% \mathrm{~B} 8$.pdf (accessed 31 December 2019). (In Russian).

3. Roylance W. Davos was all about globalization 4.0, so what does it mean? Diplomati courier. March 13. 2019. Available at: https:/www.diplomaticourier.co $\mathrm{m} /$ posts/davos-was-all-about-globalization-4-0-so-what-does-it-mean (accessed 31 December 2019).

4. Eggel D., Galvin M. Globalisation unbound: transnational flows in the Digital Era. Global Challenges, 2018, iss. 3, March 2018. Available at: https://globalchalleng es.ch/issue/3/globalisation-unbound-transnational-flows-in-the-digital-era/ (accessed 31 Decembber 2019). 
Черная И. П. Инновационные контуры геоэкономической конкурентоспособности России в цифровой эпохе

5. Petersen Th. Digital Economy: How is digitalization changing global competitiveness and economic prosperity? Available at: https://ged-project.de/blogposts en/digital-economy-how-is-digitalization-changing-global-competitiveness-and-econo mic-prosperity/?cn-reloaded=1 (accessed 31 December 2019).

6. Mühleisen M. The long and short of the digital revolution. Finance \& Development, June 2018, vol. 55, no. 2. Available at: https://www.imf.org/external/pu bs/ft/fandd/2018/06/impact-of-digital-technology-on-economic-growth/muhleisen.pdf (accessed 31 December 2019).

7. Baldwin R. Velikaya konvergentsiya: informatsionnye potoki i novaya globalizatsiya [The Great Convergence: information flows and the new globalization]. Moscow: Delo Publishing House, 2018. 416 p.

8. The bigger picture. How globalization, digitalization and demographic change challenge the world. Available at: https://ged-project.de/research/studies/the-biggerpicture/ (accessed 31 December 2019).

9. Bereznoy A. Transnatsional'nyi biznes v epokhu global'noi tsifrovoi revolyutsii [Multinational business in the era of global digital revolution]. Mirovaya ekonomika $i$ mezhdunarodnye otnosheniya [World economy and international relations], 2018, vol. 62, no. 9 , pp. 5-17.

10. Your guide to driving digital innovation. Available at: https://www.mendix.com/digital-innovation/\#targetText=What\%20is\%20Digital\%20I nnovation $\% 3 \mathrm{~F}$,-Irrespective $\% 20$ of $\% 20$ the \& targetText $=\mathrm{At} \% 20 \mathrm{its} \% 20$ core $\% 2 \mathrm{C} \% 20$ digital\%20innovation,new\%20products\%20or\%20business\%20models (accessed 31 December 2019).

11. The rise of digital protectionism. From Greenberg Center for Geoeconomic Studies. Insights from a CFR Workshop. Available at: https://www.cfr.org/report/rise -digital-protectionism (accessed 31 December 2019).

12. Chernaya I.P. Geoekonomicheskie faktory razvitiya ekonomicheskikh tsiklov v sovremennuyu epokhu [Geoeconomic factors of economic cycles in the modern era]. Tamozhennaya politika Rossii na Dal'nem Vostoke [Russian Customs policy in the Far East], 2018 no. 2 (83), pp. 15-24.

13. Forecast of the development of world relations in the 21 st century. In: Chertok E., ed. Kosmonavtika XXI veka. Popytka prognoza razvitiya do $2101 \mathrm{~g}$. [Cosmonautics of the 21st century. Attempt to forecast development until 2101]. Moscow: RTSoft Publ., 2010, pp. 483-554.

14. IMF Annual Report 2018. Available at: https://www.imf.org/external/pu bs/ft/ar/2018/eng/assets/pdf/imf-annual-report-2018-ru.pdf (accessed 31 December 2019). (In Russian).

15. Armament and disarmament. Available at: https://www.sipri.org/research /armament-and-disarmament (accessed 23 October 2019). 
16. Aptekman A., Kalabin V., Klintsov V., Kuznetsova E., Kulagin V., Yasenovets I. Tsifrovaya Rossiya: novaya real'nost' [Digital Russia: A New Reality. Digital McKinsey]. Available at: https://www.mckinsey.com/ru/ /media/McKinsey/Locations /Europe\%20and\%20Middle\%20East/Russia/Our\%20Insights/Digital\%20Russia/DigitalRussia-report.ashx (accessed 31 December 2019).

17. Competition in the digital age: Strategic challenges for the Russian Federation. Available at: https://www.vsemirnyjbank.org/ru/country/russia/publication/ competingin-digital-age (accessed 31 December 2019). (In Russian).

18. The digital potential of the EABR member countries. Center for Integration Studies. June 2019. Available at: https://eabr.org/upload/iblock/551/EABR_D igital_Potential_06_2019.pdf (accessed 31 December 2019). (In Russian). 